\title{
Determination of Volatile Organic Compounds (VOCs) Using Tedlar Bag/Solid-phase Microextraction/Gas Chromatography/Mass Spectrometry (SPME/GC/MS) in Ambient and Workplace Air
}

\author{
Jae-Hwan Lee, 'Seung Man Hwang, Dai Woon Lee, $;$ and Gwi Suk Heo ${ }^{*}$ \\ Division of Chemical Metrologv and Materials Evaluation. \\ Korea Research Institute of Standards and Science, Taejon 305-340. Korea \\ 'Department of Chemistrv, Konsei Lniversity, Seoul 120-749. Korea \\ Received November 12, 2001
}

\begin{abstract}
SPME techniques have proven to be very useful tools in the analysis of wide VOCs in the air. In this study, we estimated VOCs in ambient and workplace air using a Tedlar ba/SPME/GC/MS system. The calibration curve was set to be linear over the range of $1-30 \mathrm{ppbv}$. The detection linits ranged from $10 \mathrm{ppty}$ to $0.93 \mathrm{ppbv}$ for all VOCs. Reproducibility of TO-14 target gas mixtures by SPME/GC/MS averaged at 8.8 R.S.D (\%). Air toxic VOCs (hazardous air pollutants. HAPs) containing a total of forty halohydrocarbons. aromatics. and haloaro-natic carbons could be analyzed with significant accuracy, detection limit and linearity at low ppby level. Only reactive VOCs with low molecular weight. such as chloromethane. vinylchloride. ethylchloride and 1,2-dichloroethane. yielded relatively poor results using this technique. In ambient air samples. ten VOCs were identified and quantified after extemal calibration. VOC concentration in ambient and workplace air ranged from 0.04 to 1.85 ppbv. The overall process was successfully applied to identify and quantify VOCs in anbient/workplace air.
\end{abstract}

Keywords : VOCs. Tedlar bag. GCMS. Solid-phase microextraction (SPME). Detection limit.

\section{Introduction}

Volatile organic compounds (VOCs) in ambient air originate from various biogenic and anthropogenic sources. The US Clean Air Act Amendments (CAAA) of 1990 lists 189 chemicals as hazardous air pollutants (HAPs). and nearly 100 of them have been classified as VOCs.- This class of compounds typically has boiling points in the range of $50-260^{\circ} \mathrm{C}^{3}$ and vapour pressures greater than 0.1 torr. $^{4}$ Exposure to low-level VOC concentrations in indoor air is suspected to contribute to a variety of non-specific symptoms such as headache. and eye. nose and skin irritations. which are categorized as part of "sick building ștndrome":

The 1990 CAAA and California Safe Drinking Water and Toxic Enforcement Act of 1986 require a large number of various VOCs to be monitored. ${ }^{6}$ The majority of the methods developed for VOCs in air have been canisterbased $^{7.5}$ or sorbent-based ${ }^{1(1.13}$ and or polymeric bag. ${ }^{1.16}$ In canister-based methods. a whole air sample is drawn into a metal canister. and a portion of it is then analyzed using methods that involve passing the air through either a cryotrap or a sorbent bed. thereby focusing the VOCs prior to analysis using gas chromatography (GC). In the sorbentbased method an air sample is pulled directly through a glass or metal tube that is packed with an appropriate sorbent material. Thermal desorption is usually used to transfer the analytes to the GC column. In both canister and sorbentbased methods. samples can not be directly analyzed without the application of preconcentration and sample pretreatment tecluniques because the concentra-tion of analytes is lower than the detection limit. ${ }^{17}$ Thus. it is necessary to perform sample preparation steps prior to analysis. Conventional measures of preconcentration involve using cryogens such as liquid nitrogen, argon, or $\mathrm{CO}$, to condense VOCs onto some inert solid surface as air sample flowing through. ${ }^{18}$ However. these analytical methods require various sample preparation steps. and preconcentra-tion devices such as cryotrap and peltier cooler system, and as such, they are also timeconsuming.

Recently a new extraction teclunique called solid-phasemicroextraction (SPME) has been developed by Pawliszyn et al. ${ }^{19.31}$ In this technique. sampling. extraction and concentrations are incorporated into a single step and the use of solvents. where possible environmental pollutants may reside is eliminated. A fused-silica fiber. coated with a polymer. is exposed to the gaseous sample or immersed in an aqueous sample to extract the analytes. ${ }^{21.25}$ The fiber is then injected into the gas chromatography injection port for thermal desorption and analysis.

SPME is based on partition equilibrium of the analytes between the aqueous or gases sample and the polymer coating of a fused-silica fiber. ${ }^{2}$ In normal operation. the fiber is exposed to the sample media until equilibrium is reached. but the time needed to reach the adsorption equilibrium between the sample and the polymer coating can be very long. In these situations. shortening the adsorption time and working in non-equilibrium conditions are desirable ${ }^{27}$

Extensive studies on the SPME technique. including theory. optimization. its automation and the dynamics of adsorption. as well as a number of applications have been summarized in a recent book. ${ }^{2}$ SPME has been applied to 
the analysis of different compounds including polynuclear aromatic hydrocarbons (PAHs) and polychlorinated hydrocarbons, ${ }^{37.99}$ volatile chlorinated hydrocarbons, ${ }^{3(1)}$ phenols, ${ }^{31.33}$ pesticides,${ }^{3+47}$ organoarsenic compounds. ${ }^{48}$ organotin compounds. ${ }^{11}$ fatty acids, ${ }^{51}$ tetraethyllead ${ }^{\$ 1}$ volatile carbonyl compounds. ${ }^{5-2}$ trimethylamine, ${ }^{\hat{s} 3} \mathrm{drugs}^{5+4}$ and volatile organic compounds (VOCs)

This study reported to evaluate a wide range of VOCs by /SPME/GC/MS system using a Tedlar bag. A collection of VOCs, chosen as good representatives of the entire class of VOCs, is listed in the EPA method TO-14 (see Table 1). These groups include representatives of all classes of VOCs: freons. trihalomethanes as well as other halogenated compounds. and aromatic and haloaromatic compounds. GC/MS analysis of VOCs was carried out using a capillary colunn after ambient/workplace air was collected on the Tedlar bag. and were then extracted using SPME

\section{Experimental Design}

Chemicals and materials. TO- 14 Standard gas mixture cylinder (forty VOCs in nitrogen) was purchased from Matheson Gas Products (San Francisco. CA). The information on target VOCs is listed on Table 1. The Tedlar bag ( 1 and $5 \mathrm{~L}$ ) was supplied by SKC (SKC. USA). The gas-tight syringes $(1,10$ and $50 \mathrm{~nL})$ were supplied by Graf FORTUNA (Germany), while the $2 \mathrm{~L}$ gas syringe was obtained from Hamilton (MODEL S-2000, Reno, Nevada. USA). A DCINA type air sampler was obtained from Japan.

SPME fibers. The SPME holder for manual sampling was purchased from Supelco. Polydimethylsiloxane (PDMS) (100 $\mu \mathrm{m}$ film thickness). polyacrylate (PA) $(85 \mu \mathrm{m}$ film thichness), Carboxen-PDMS (CAR/PDMS) (75 $\mu \mathrm{m}$ film thickness), and Carbowax-divinylbenzene (CW/DVB) (65 $\mu \mathrm{m}$ film thickness) fibers were obtained from Supelco (Bellefonte, PA. USA). Four fibers were tested and com-pared. All the SPME fibers were conditioned in the hot injector portion of the gas chromatograph according to instructions provided by the supplier.

Standard preparation and GC/MS analysis. Analytical gas standards were prepared using volumetric injection. A known amount of TO-14 standard gas mixture was loaded into $1 \mathrm{~L}$ Tedlar bag through a septum using a gas-tight strringe. After the sample preparation. the SPME syringe needle was inserted into a Tedlar bag filled with standard gas mixture through a septum. The CAR/PDMS SPME fiber was then lowered into the standard gas by depressing the plunger. Target VOCs were partitioned into the polymeric coating of the fiber until equilibrium was reached. The plunger was then withdrawn. and the needle was removed from the standard gas Tedlar bag. After extraction for $15 \mathrm{~min}$. the fiber was directly exposed for $5 \mathrm{~min}$ at $250^{\circ} \mathrm{C}$ in the $\mathrm{GC}$ injector. Thermal desorption of analytes was carried out for $3 \mathrm{~min}$. The environmental air samples (real sample) were obtained in $5 \mathrm{~L}$ Tedlar bag. The environmental air samples in the Tedlar bag then were extracted using the same procedure followed in SPME extraction from a standard gas Tedlar bag.

Analyses were carried out on a Varian $3400 \mathrm{CX}$ gas cluromatograph (GC), which was connected to a Varian Saturn 2000 mass spectrometer. Ionization mode of mass spectrometer was EI (electron impact) at $70 \mathrm{eV}$. The mass range scauned was from $\mathrm{m} / \mathrm{z} 35$ to $280 \mathrm{amu}$. The gas chromatograph/ mass spectrometer interface temperature was 200 while the ion source temperature was $195^{\circ} \mathrm{C}$. The GC injection port was maintained at a temperature of $250{ }^{\circ} \mathrm{C}$ for thermal desorption. Separation was carried out on a $60 \mathrm{~m} \times 0.32$ $\mathrm{mm} \times \mathrm{l} \mu \mathrm{m}$ DB-l capillary column (J \& W Scientific. USA), while column oven temperature was initially held at $40^{\circ} \mathrm{C}$ for $4 \mathrm{~min}$. programmed to $190^{\circ} \mathrm{C}$ at a rate of $7 / \mathrm{min}$. and then to $250^{\circ} \mathrm{C}$ at $10^{\circ} \mathrm{C} / \mathrm{min}$. The sample was quantified by selected ion monitoring (SIM). Quantification of the ions $(\mathrm{m} / \mathrm{z})$ is shown in Table l. High-purity helium $(99.995 \%)$ was used as a carrier gas at a flow-rate of $1 \mathrm{~mL} / \mathrm{min}$. Outlet split flow and septum purge flow was $10 \mathrm{~mL} / \mathrm{min}$ and $3 \mathrm{~mL} /$ min. respectively.

Storage stability of target VOCs in Tedlar bag. 1-liter Tedlar bag was used to compare the stability of target VOCs over a $46 \mathrm{~h}$ period ( 5 Tedlar bags: zero air using a ligh purity nitrogen gas matrix, other 5 Tedlar bags: $25 \%$ humidified with a real air matrix). The target VOCs were prepared along with concentrations of $30 \mathrm{ppbv}$ and stored in room temperature (exactly $19^{\circ} \mathrm{C}$ ). The storage test was conducted over a 46 hour period. with analysis at $0,3,6.20$, and $46 \mathrm{~h}$. The Tedlar bags were vacuumed to remove air. water vapor, and any organic compounds before use.

Application to ambient/workplace air. The Tedlar bag has long been used in sampling and analyzing source emissions for pollutants. It was one of the recommended sampling techniques in the EPA method $18^{63}$. The samples were collected using a $5 \mathrm{~L}$ Tedlar bag during rush hours at the road and in an organic laboratory. Ambient/workplace air samples were drawn through $5 \mathrm{~L}$ Tedlar bag using a DCI-NA type air sampler. operating at a flow-rate of $500 \mathrm{~mL} / \mathrm{min}$. The relative humidity of ambient and workplace (organic laboratory) air sample was $33 \%$ and $44 \%$. respectively. After ambient/ workplace air was sampled. the SPME fiber was then exposed to the air sample for $15 \mathrm{~min}$ and directly exposed to the hot injector of the GC system for analysis. Thermal desorption of the target VOCs was carried out at $250^{\circ} \mathrm{C}$.

\section{Results and Discussion}

Identification of target VOCs by GC/MS. A comparison of total ion chromatogram between the selected ion moni-toring (SIM) and scan mode is illustrated in Figure 1. The SIM mode gave sharper chromatographic peaks for target VOCs than the scan mode. Scan mode analysis did not produce a satisfactory sensitivity at $1 \mathrm{ppbv}$. In trace analysis. GC/MS scan mode was usually difficult for the determination analysis in the complex matrix. All the experiments were carried out by SIM mode in the quantitative analysis.

Only reactive VOCs with low molecular weight. such as chloromethane. vinylchloride. ethylchloride and 1.2-dichloro- 
ethane. showed relatively poor results when Tedlar/SPME technique was used. These compounds were not detected within the range of the calibration curve.

Selection of SPME fiber. PDMS. PA, CAR/PDMS and CW/DVB coatings are commercially available for SPME. PDMS coating can be applied in non-polar organic compounds such as VOCs. polycyclic aromatic hydrocarbons. benzene, toluene. ethylbenzene. xylene. organochlorine pesticides. ${ }^{6+} \mathrm{PA}$ coating is applicable to polar organic compounds such as triazines. organophosphorous pesticides and phenols. ${ }^{6+}$ CAR/PDMS coating can be applied to VOCs and hydro-carbons. CW/DVB is applicable for polar organic compounds such as alcohols, ketones, nitroaromatics. ${ }^{6-1}$

The sensitivity and selectivity of the four types of coating to extract target VOCs from samples were evaluated at 10 ppbv: and the results were illustrated by plotting GC peak area with different type of SPME fibers (Figure 2). The four types of fibers used in this experiment are as follows: $75 \mu \mathrm{m}$ CAR/PDMS, $65 \mu \mathrm{m}$ CW/DVB, $100 \mu \mathrm{m}$ PDMS, and $85 \mu \mathrm{m}$ PA. Total ion chromatogram obtained at $10 \mathrm{ppbv}$ using four different SPME fibers are shown in Figure 3.

The $75 \mu \mathrm{m}$ CAR/PDMS fiber proved to be most effective for target VOCs. However, the PDMS and polyacrylate (PA) fiber revealed to have low affuity for all VOCs. The decreasing order of affinity is as follows: $75 \mu \mathrm{m} \mathrm{CAR} /$ PDMS. then $65100 \mu \mathrm{m}$. CW/DVB, $100 \mu \mathrm{m}$ PDMS and. finally, the $85 \mu \mathrm{m}$ polyacry late fiber.

Equilibrium of target VOCs. To determine the optimum extraction tume, intervals of $5,10.15,20,25.30,35.40$ and 45 mun were tested and compared. The extraction tume was monitored by plotting the peak area against adsorption time. The equilibrium was not reached until according to our timeadsorption profile for target VOCs. Equilibrium was not reached even after $45 \mathrm{~min}$ owing to the large affinity of

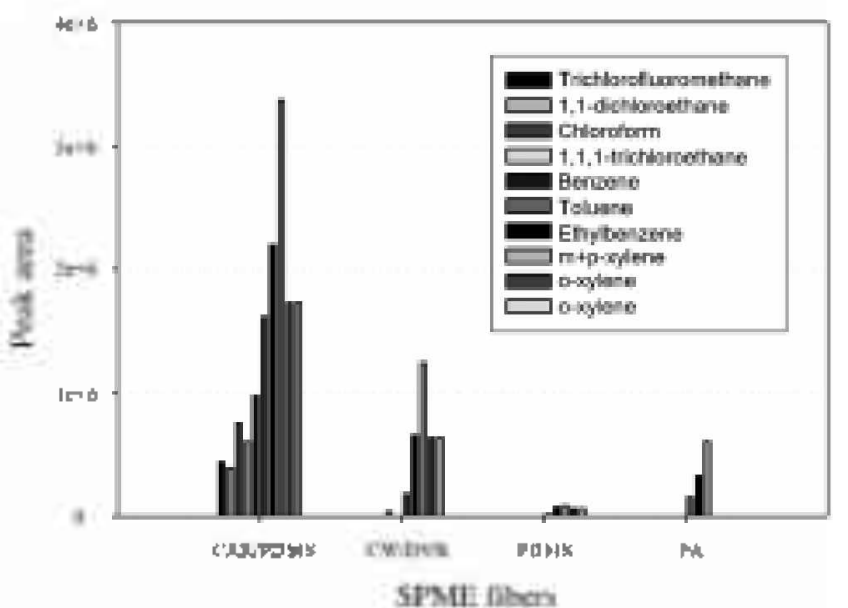

Figure 2. Relative extraction efficiency for selected VOCs at 10 ppbe using four SPME fibers $(75 \mu \mathrm{m}$ CAR/PDMS, $65 \mu \mathrm{m} \mathrm{CW} /$ DVB, $100 \mu \mathrm{m}$ PDMS, $85 \mu \mathrm{m}$ PA).

compounds towards the CAR/PDMS fiber. An extraction tume of $15 \mathrm{~min}$ was selected although equilibrium was yet to be reached at this time. For routme analysis, it was not necessary to reach a complete equilibrium as long as the exposure time of the fiber was kept exactly constant. Detailed results are shown in Figure 4.

Carryover (memory effect) for $15 \mathrm{~mm}$ adsorption of target VOCs in SPME fiber did not appear in these conditions. This was evaluated by desorbing the same fiber for the second time after the first desorption at hot GC injector.

Calibration curves and detection limit. Forty target compounds selected are listed in Table 1 . They represent various groups of VOCs which are ubiquitous components in ambient air. To demonstrate the reliability of this SPME technique method. precision, correlation coefficients and

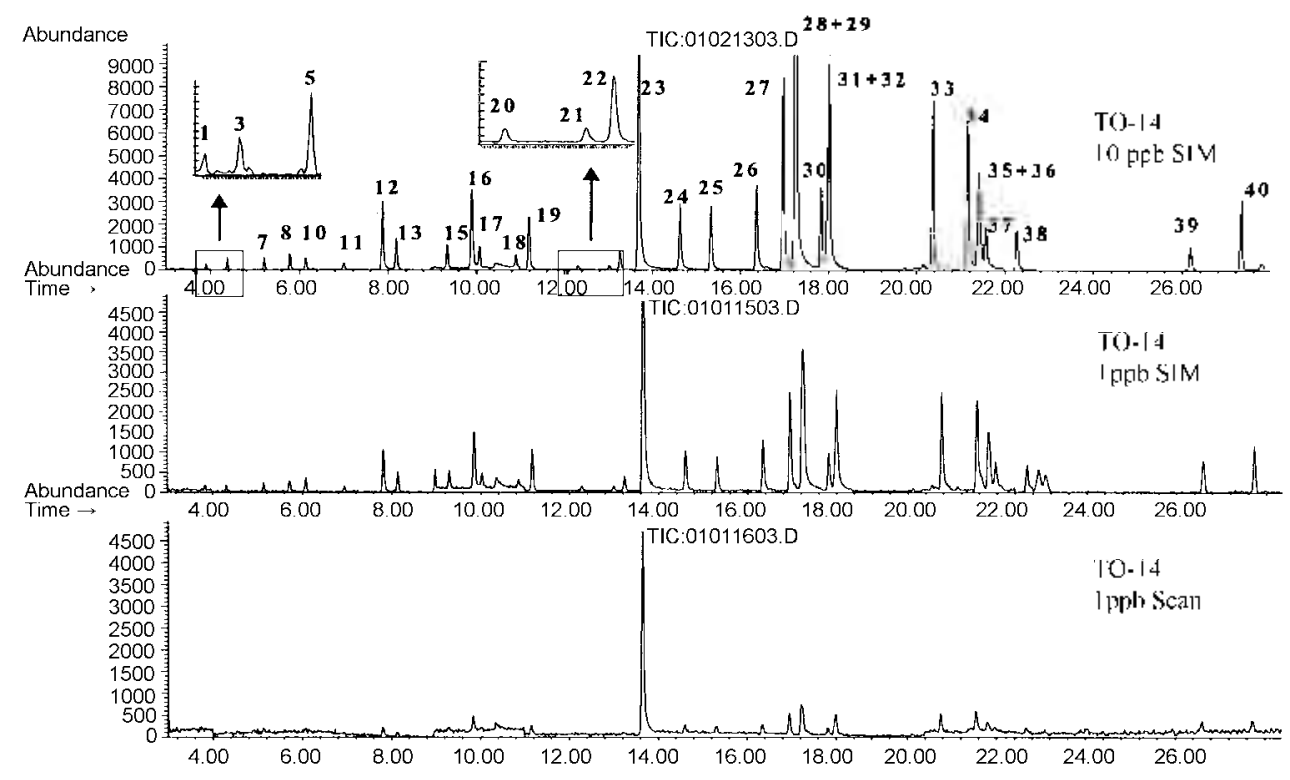

Figure 1. Total ion chromatogram of forty VOCs standard obtained from $10 \mathrm{ppbv}$ concentration by GC/MS-SIM mode. The numbers of VOC's were as listed in rable 1 . 


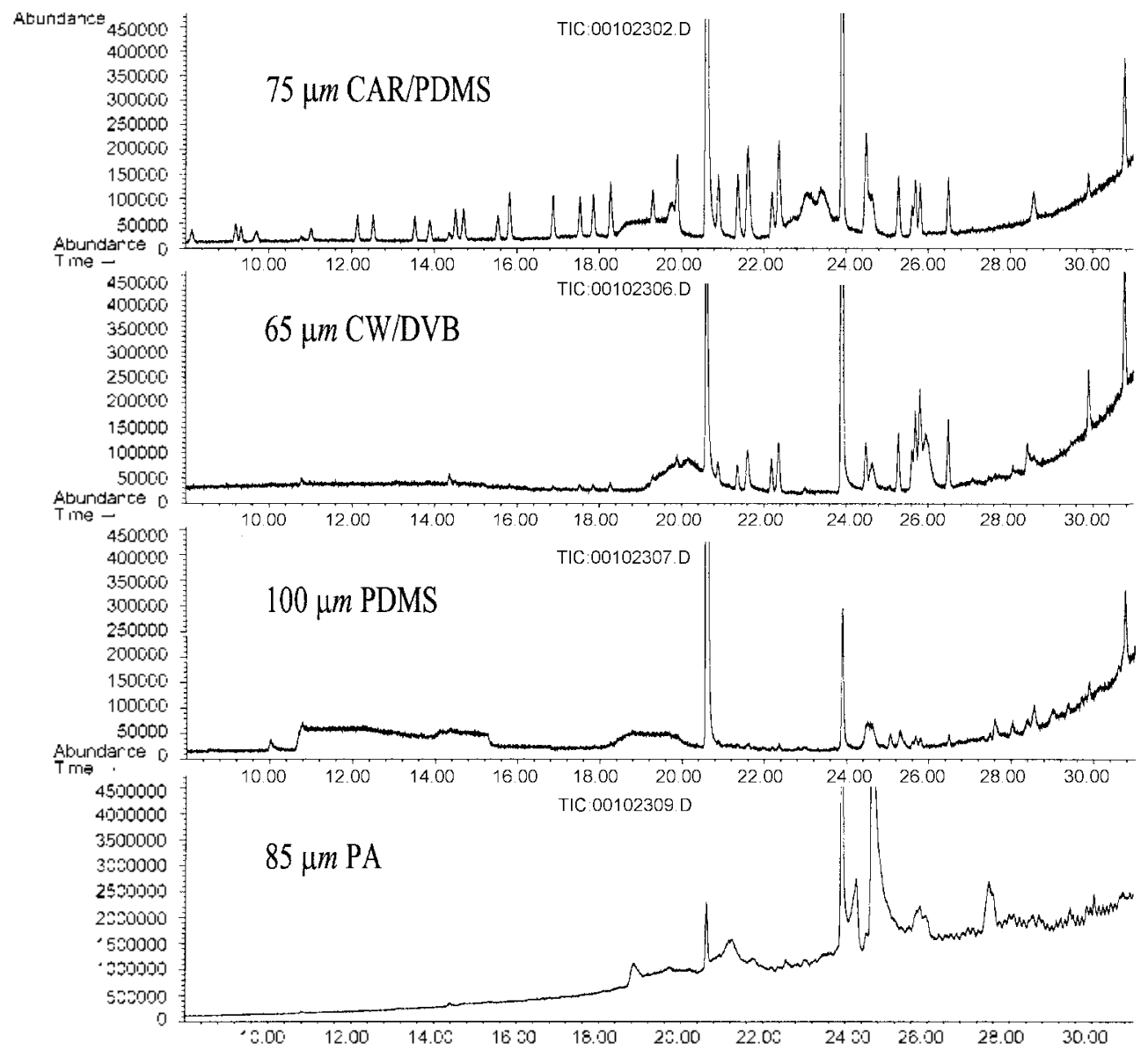

Figure 3. GC/MS chromatogram of the target VOCs by comparison of selectivity and sensitivity: $75 \mu \mathrm{m}$ CAR/PDMS: $65 \mu \mathrm{m}$ CW/DVB; 100 m $\mathrm{mDMS} ; 85, \mathrm{~m}$ PA.

detection limits were determined using Tedlar bag/SPME. The calibration for all target VOCs was linear with a correlation coefficient of at least 0.990 except 1.2 -dichloro1,1.2,2-tetrafluoromethane $(0.948)$ over the range of $1-30$ ppbv: Detection limit values for target VOCs were shown from $10 \mathrm{ppty}$ to $0.93 \mathrm{ppbv}$. The detection limit was estimated to be greater than 3 on the basis of the $\mathrm{S} / \mathrm{N}$ ratio. The precision obtained, expressed as relative standard deviation. was lower than $10 \%$ when Tedlar bag/SPME method was used. Three replicate analysis for calibration of target VOCs standard gas was done in this study. Four compounds namely. clloromethane. vinylchloride. ethylchloride and 1. 2-dichloroethane, were not detected in the range of 1-30 ppbv: Detailed results for all VOCs were sunmmarized in Table 1.

Storage stability in Tedlar bag. Evaluating temperature and relative humidity is very important in extracting target VOCs using an SPME fiber. Chai et al. reported that humidity and temperature cause the amount of analytes adsorbed in the fiber coating to change significantly. ${ }^{5}$ They concluded that relative humidity only reduces the amount extracted at room temperature by less than $10 \%$ at up to $75 \%$ relative humidity. They also reported that the lower the temperature and hunidity, the more analytes are adsorbed by

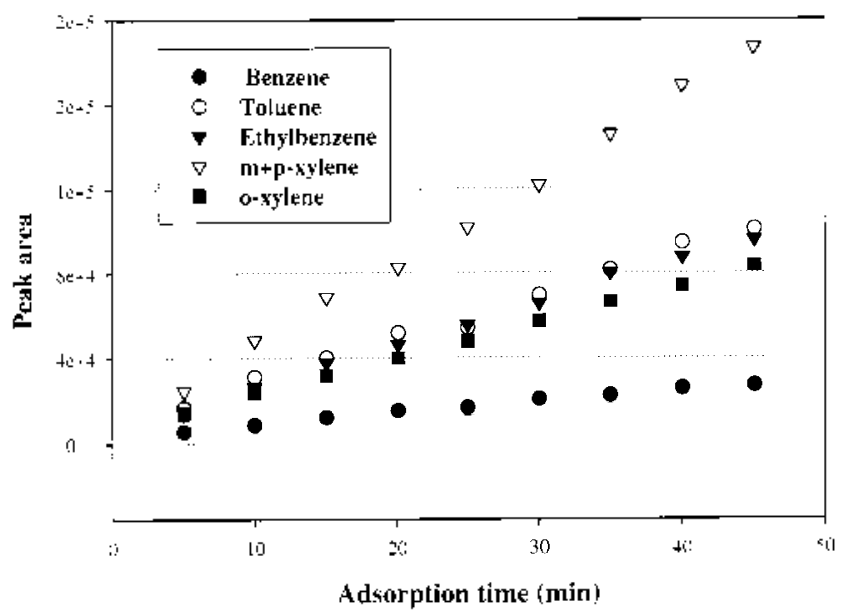

Figure 4. Estraction time profile for selected VoCs at $10 \mathrm{ppbv}$ using a $75 \mu \mathrm{m}$ CAR/PDMS SPME fiber.

the SPME fiber coating.

The results of storage stability at different matrix conditions in this study using a $\mathrm{l} \mathrm{L}$ Tedlar bag revealed a very similar stability for target VOCs. There was no significant difference between high purity nitrogen gas matrix and real air matrix at $20^{\circ} \mathrm{C}$. 
Table 1. Lists of US EPA TO-14 VOCs, limit of detection and linearity for target compounds by Tedlar bag/SPME/GC/MS.

\begin{tabular}{|c|c|c|c|c|c|c|}
\hline No & Compounds & R.T (min) & $Q$ ions & $\operatorname{RSD}(\%)(n=3)$ & $\mathrm{LOD}^{a}(\mathrm{ppbv})$ & $r^{2}$ \\
\hline 1 & Dichlorodifluoromethane & 3.71 & 85 & 7 & 0.18 & 0.9950 \\
\hline 2 & Chloromethane & $--^{b}$ & - & - & - & \\
\hline 3 & 1,2-Dichloro-1,1,2,2-tetrafluoromethane & 3.96 & 135 & 9 & 0.27 & 0.9476 \\
\hline 4 & Vinylchloride & - & - & - & - & - \\
\hline 5 & Bromomethane & 4.4 & 94 & 7 & 0.19 & 1.0000 \\
\hline 6 & Ethyl chloride & - & - & - & - & - \\
\hline 7 & Trichlorofluoromethane & 5.28 & 101 & 1 & 0.02 & 0.9992 \\
\hline 8 & 1,1-Dichloroethene & 586 & 96 & 5 & 0.15 & 0.9998 \\
\hline 9 & Methylene chloride & 5.95 & 49 & 32 & 0.93 & 0.9964 \\
\hline 10 & 1,1,2-Trichloro-1,2,2-trifluoroethane & 6.22 & 151 & 11 & 0.32 & 0.9949 \\
\hline 11 & 1,1-Dichloroethane & 7.13 & 63 & 4 & 0.50 & 0.9997 \\
\hline 12 & cis-1,2-Dichloroethylene & 7.95 & 61 & 19 & 0.03 & 1.0000 \\
\hline 13 & Chlorofonm & 8.26 & 83 & 6 & 0.01 & 0.9995 \\
\hline 14 & 1,2-Dichloroethane & - & - & - & - & - \\
\hline 15 & 1,1,1-Trichloroethane & 9.41 & 97 & 5 & 0.14 & 0.9991 \\
\hline 16 & Benzene & 9.96 & 78 & 9 & 0.01 & 0.9984 \\
\hline 17 & Carbon tetrachloride & 10.14 & 117 & 14 & 0.39 & 0.9994 \\
\hline 18 & 1,2-Diclloropropane & 10.96 & 76 & 6 & 0.16 & 0.9968 \\
\hline 19 & Trichloroethylene & 11.26 & 130 & 2 & 0.05 & 0.9999 \\
\hline 20 & cis-1,3-Dichloropropene & 12.38 & 75 & 9 & 0.24 & 0.9993 \\
\hline 21 & trans-1,3-Dichloropropene & 13.09 & 75 & 3 & 0.07 & 0.9992 \\
\hline 22 & 1,1,2-Trichloroethane & 13.34 & 97 & 8 & 0.19 & 0.9978 \\
\hline 23 & Tolnene & 13.76 & 91 & 6 & 0.01 & 0.9996 \\
\hline 24 & 1,2-Dibromoethane & 14.71 & 109 & 2 & 0.01 & 0.9995 \\
\hline 25 & Tetrachloroethy lene & 15.41 & 166 & 4 & 0.01 & 0.9987 \\
\hline 26 & Chlorobenzente & 16.45 & 112 & 9 & 0.22 & 0.9998 \\
\hline 27 & Ethylbenzene & 17.05 & 91 & 7 & 0.01 & 0.9996 \\
\hline $28+29$ & $m+p$-Xylente & 17.33 & 91 & 14 & 0.02 & 0.9999 \\
\hline 30 & Styrente & 17.93 & 104 & 3 & 0.01 & 0.9979 \\
\hline 31 & 1,1,2,2-Tetrachloroehtane & 18.06 & 83 & 26 & 0.03 & 0.9999 \\
\hline 32 & $o$-Xylene & 18.10 & 91 & 14 & 0.02 & 0.9995 \\
\hline 33 & 1,3,5-Trimethylbenzene & 20.46 & 105 & 11 & 0.01 & 1.0000 \\
\hline 34 & 1,2,4-Trimethylbenzene & 21.26 & 105 & 5 & 0.01 & 0.9997 \\
\hline 35 & Benzylchloride & 21.50 & 91 & 19 & 0.02 & 0.9993 \\
\hline 36 & $m$-Dichlorobenzene & 21.53 & 146 & 3 & 0.08 & 0.9999 \\
\hline 37 & $p$-Dichlorobenzene & 21.68 & 146 & 21 & 0.02 & 0.9987 \\
\hline 38 & $o$-Dichlorobenzene & 22.37 & 146 & 17 & 0.02 & 0.9990 \\
\hline 39 & 1,2,4-Trichlorobenzene & 26.32 & 180 & 20 & 0.02 & 0.9967 \\
\hline 40 & Hexachloro-1,3-butadiene & 27.45 & 225 & 19 & 0.01 & 0.9997 \\
\hline
\end{tabular}

"3 replicate analysis. ${ }^{b}$ not detected in the range of $\mathrm{l}-30 \mathrm{ppbv}$ (calibration range)

In the air matrix, styrene. benzyl chloride and 1.2,4-trichlorobenzene yielded a significant loss in $50 \mathrm{~h}$. Styrene showed that a $22 \%$ loss in the first $2 \mathrm{~h}$ while an additional 43 $\%$ was lost in the next $50 \mathrm{~h}$. Benzyl chloride yielded loss of $22 \%$ in the furst $2 \mathrm{~h}$ while an additional $40 \%$ was lost in the next $9 \mathrm{~h}$. Similarly, $31 \%$ of the $1.2,4$-trichlorobenzene was lost in the first $2 \mathrm{~h}$ while an additional $43 \%$ was lost in the next $9 \mathrm{~h}$. Dichlorobenzenes (ortho, meta and para-) revealed a loss of $14 \%$ in the first $2 \mathrm{~h}$ while an additional $27 \%$ was lost in the following $9 \mathrm{~h}$. These results indicate that these compounds cannot be stored for a long period probably because of diffusion through the Tedlar bag wall or adsorption onto it. However. BTEX compounds (benzene, toluene. ethylbenzene and $m, p$-xylenes) proved very stable while the other target VOCs manifested an average loss of $17 \%$ in 50 h. Detailed results of storage stability are shown in Figure 5.

Application of field sampling (ambient air and workplace air). SPME was applied to real sample (ambient/workplace air) using the same conditions employed in calibrating the method. GC/MS chromatogram results for real samples are shown in Figure 6. Ten VOCs were detected in ambient air. BTEX compounds (benzene. toluene. ethyl-benzene and $m+$ $p$-xylene). trimethylbenzene and trichloro-benzene were found to be important pollutants. VOC concentration detected in ambient air ranged from 0.16 to $1.85 \mathrm{ppbv}$.

GC/MS cluromatogram results for workplace air revealed a 
very similar pattern to that of ambient air. Nine VOCs were detected in workplace air. VOC concentration in workplace air ranged from 0.04 to $1.22 \mathrm{ppbv}$. A sunmary of all the results is shown in Table 2

\section{Conclusions}

Various VOCs were estimated using a conmon GC/MS
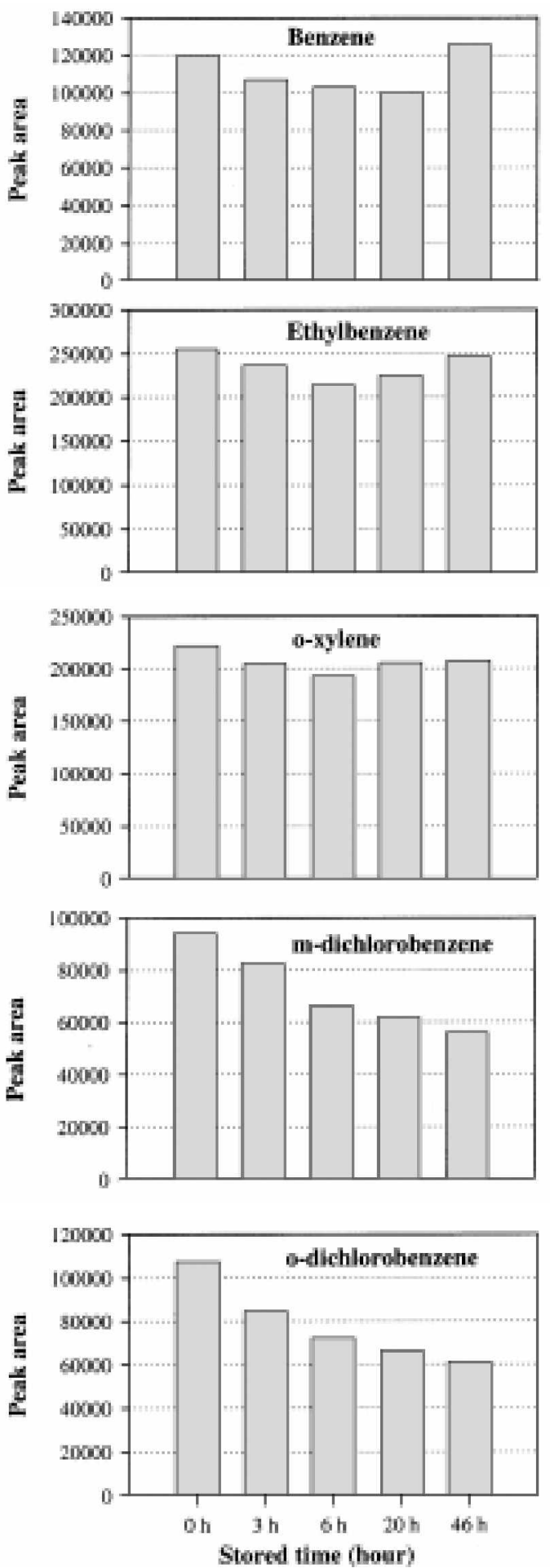

system with Tedlar bag /SPME without classical solvent consumption for sample preparation or using cryogenic technique for concentration in ambient/workplace air. A linear working range of $1-30 \mathrm{ppbv}$ was established. Calibration yielded a linear curve over this range except 1.2-dichloro1.1.2.2-tetrafluoroethane. This method showed a precise average of $8.8 \%$ relative standard deviation. Detection limits ranged from $10 \mathrm{pptv}$ to $0.93 \mathrm{ppbv}$. VOCs with low molecular
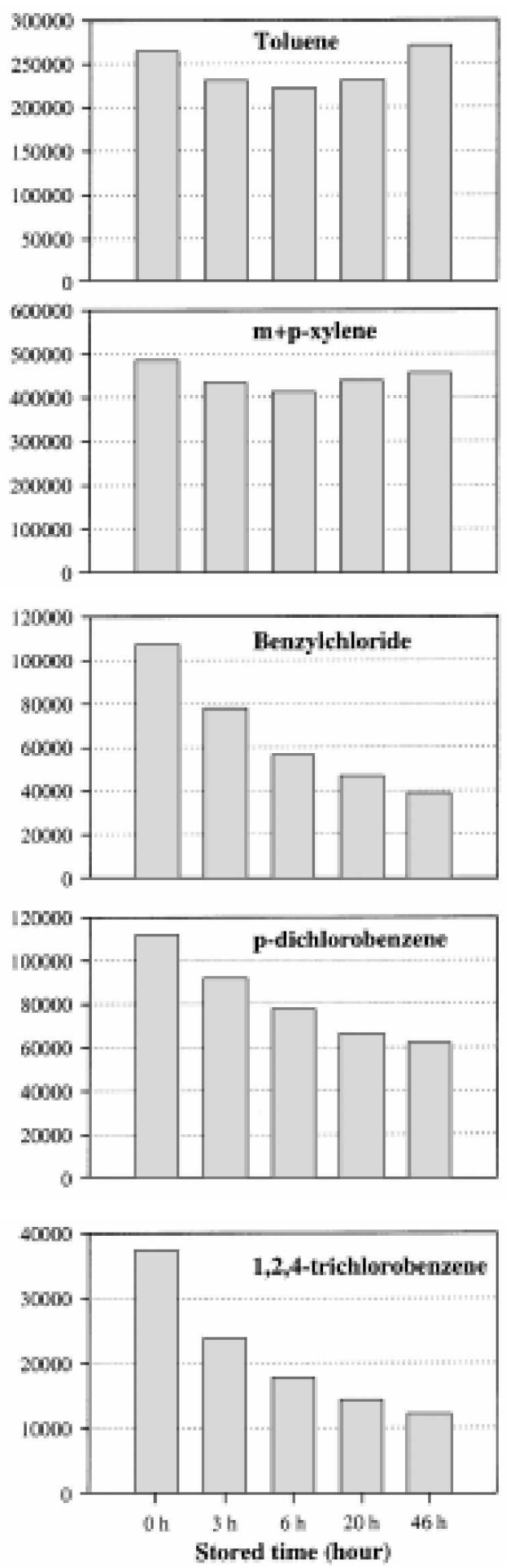

Figure 5. Stability of selected VOCs in $1 \mathrm{~L}$ Tedlar bag with real air matrix (RH $25 \%$ ) at 30 ppby. 


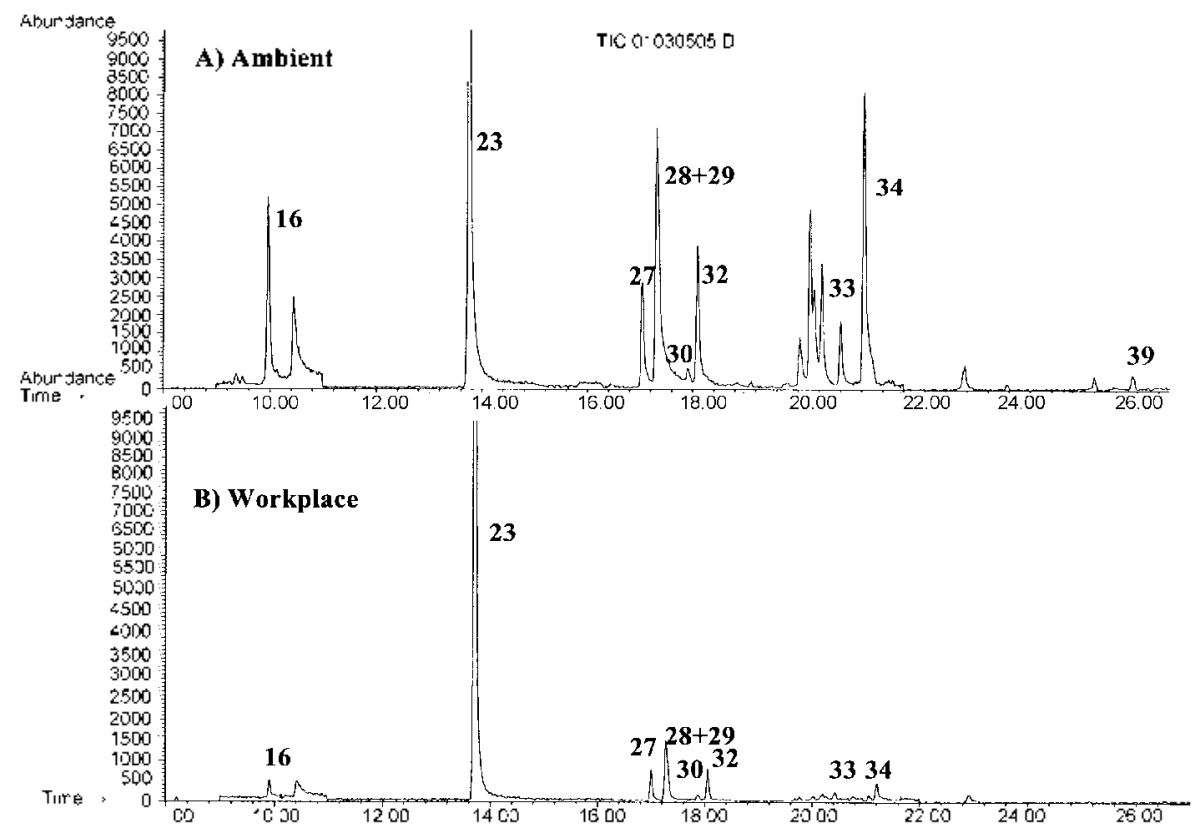

Figure 6. (A) GC/MS-SIM chromatogram of VOCs extracted from ambient air using SPME fïber $75 \mu m$ CARPDMS. Analytes in order of elution were: (16) benzene, (23) toluene, (27) ethylbenzene, (28+29) $\mathrm{m}+\mathrm{p}$-xylene, (32) o-xylene, (33) 1,3,5-trimethylbenzene, (34) $1,2.4-$ trimethylbenzene, (39) 1,2,4-trichlorobenzene. (B) GC/MS-SIM chromatogram of VOC's extracted from workplace. Analytes in order of elution were: (16) benzene, (23) toluene, (27) ethylbenzene, (28+29) $\mathrm{m}+\mathrm{p}-\mathrm{xy} l \mathrm{lene},(32)$ o-xylene, (33) $1,3,5$-trimethylbenzene, (34) $1,2,4-$ trimethylbenzene.

Table 2. The results of concentration in ambient and laboratory air

\begin{tabular}{|c|c|c|c|c|c|}
\hline No & Compounds & $\begin{array}{l}\mathrm{MW} . \\
(\mathrm{g} / \mathrm{mol})\end{array}$ & $\begin{array}{c}\text { VOC stanlard } \\
\text { gas conc. (ppmy p }\end{array}$ & $\begin{array}{l}\text { Conc. } \\
(\mathrm{ppbv})^{6}\end{array}$ & Conc (ppby) \\
\hline 1 & Dichlorodifluoromethane & 120.91 & 0.88 & N.D ${ }^{d}$ & N.D' \\
\hline 2 & Chloromethane & 50.49 & 0.88 & - & - \\
\hline 3 & 1,2-Diclloro-1,1,2,2-tetrafluoromethane & 170.93 & 0.95 & N.D & N.D \\
\hline 4 & Vintlchloride & 62.50 & 0.92 & - & - \\
\hline 5 & Bromomethane & 94.94 & 0.89 & N.D & N.D \\
\hline 6 & Ethyl chloride & 64.52 & 0.91 & - & - \\
\hline 7 & Trichlorofluoromethane & 137.38 & 0.95 & N.D & N.D \\
\hline 8 & 1,1-Diclloroethene & 96.95 & 0.92 & N.D & N.D \\
\hline 9 & Methylene chloride & 84.94 & 0.93 & N.D & N.D \\
\hline 10 & 1,1,2-Triclloro-1,2,2-trifluoroethane & 187.38 & 0.90 & N.D & N.D \\
\hline 11 & 1,1-Diclloroethane & 98.96 & 0.88 & N.D & N.D \\
\hline 12 & cis-1,2-Dichloroethylene & 96.94 & 0.89 & N.D & N.D \\
\hline 13 & Chloroform & 119.38 & 0.90 & N.D & N.D \\
\hline 14 & 1,2-Diclloroethane & 98.96 & 0.89 & - & - \\
\hline 15 & 1,1,1-Triclloroethane & 133.41 & 0.90 & N.D & N.D \\
\hline 16 & Benzene & 78.12 & 0.90 & 0.30 & 1.85 \\
\hline 17 & Carbon tetrachloride & 153.82 & 0.90 & N.D & N.D \\
\hline 18 & 1,2-Dichloropropane & 112.99 & 0.89 & N.D & N.D \\
\hline 19 & Trichloroethylene & 131.29 & 0.88 & N.D & N.D \\
\hline 20 & cis-1,3-Dichloropropene & 110.97 & 0.85 & N.D & N.D \\
\hline 21 & trons-1,3-Dichloropropene & 110.97 & 0.85 & N.D & N.D \\
\hline 22 & 1,1,2-Trichloroethane & 133.41 & 0.82 & N.D & N.D \\
\hline 23 & Toluene & 92.15 & 0.83 & 1.22 & 0.78 \\
\hline 24 & 1,2-Dibromoethane & 187.88 & 0.82 & N.D & N.D \\
\hline 25 & Tetrachloroethylene & 165.83 & 0.81 & N.D & N.D \\
\hline 26 & Cllorobenzene & 112.56 & 0.83 & N.D & N.D \\
\hline
\end{tabular}


Table 2. Continued

\begin{tabular}{|c|c|c|c|c|c|}
\hline No & Compounds & $\begin{array}{c}\text { M.W. } \\
(\mathrm{g} / \mathrm{mol})\end{array}$ & $\begin{array}{c}\text { VOC standard } \\
\text { gas conc. (ppmy) }\end{array}$ & $\begin{array}{l}\text { Conc. } \\
(\mathrm{ppbv})^{b}\end{array}$ & Conc (ppby) \\
\hline 27 & Ethylbenzene & 106.17 & 0.80 & 0.21 & 0.62 \\
\hline $28+29$ & $m+p-X y l e n e$ & 106.17 & 0.81 & $<\mathrm{DL}^{e}$ & 0.77 \\
\hline 30 & Styrene & 104.16 & 0.84 & 0.45 & 0.56 \\
\hline 31 & 1,1,2,2-Tetrachloroehtane & 167.85 & 0.82 & N.D & N.D \\
\hline 32 & $o$-Xvlene & 106.17 & 0.82 & 0.15 & 0.55 \\
\hline 33 & 1,3,5-Trimethylbenzene & 120.20 & 0.74 & 0.04 & 0.58 \\
\hline 34 & 1,2,4-Trimethylbenzene & 120.20 & 0.72 & 0.15 & 1.82 \\
\hline 35 & Benzylchloride & 126.59 & 0.82 & N.D & N.D \\
\hline 36 & $m$-Dichlorobenzene & 147.01 & 0.70 & N.D & N.D \\
\hline 37 & $p$-Dichlorobenzene & 147.01 & 0.69 & N.D & N.D \\
\hline 38 & $o$-Dichlorobenzene & 147.01 & 0.57 & N.D & N.D \\
\hline 39 & 1,2,4-Trichlorobenzene & 181.45 & 0.59 & N.D & 0.16 \\
\hline 40 & Hevachloro-1,3-butadiene & 260.80 & 0.32 & N.D & N.D \\
\hline
\end{tabular}

"VOC standard gas (ponv concentration) was used for calibration of the analysis. The standard gas was diluted before calibration. Detailed descriptions for dilution are included in context of experimental part. "Concentrations of workplace air. "Concentrations of ambient air. "Not detected. "Lower than detection limit.

weight including chloromethane. vinylchloride, ethylchloride and 1,2-dichloroethane were not detected in the calibration range using this technique. VOC concentration in ambient and workplace air ranged from 0.04 to $1.85 \mathrm{ppbv}$. SPME proved to be a simple. inexpensive. rapid and promising analytical technique for the quantitative analysis of a wide range of VOCs present in ambient/workplace air samples. Tedlar bag/SPME/GC/MS method was proved to be useful for screening of ambient/workplace air.

\section{References}

1. Dettmer. K: Knobloch. T.: Engewald. W. F. J. Anal. Chen. 2000. 366.70 .

2. MacKensie. A. R.: Harrison. R. M.: Colbeck. I.: Hewitt. C. N. Atmos. Emiron. 1991. 25. 351

3. Holcomb L. C.: Seabrook, B. S. Indoor Emiron. 1995. 4. 7.

4. Mukund. R.: Kelly, T. I.: Gordon. S. M: Hays, M. J.: McClenny: W. A. Eniron. Sci. Technol 1995 29.183A.

5. Elke. K.: Jermann. E.: Begerow. J.: Dunemann. L. J. Chromatogr: A 1998, 826. 191

6. Troost. J. R. Anal. Chem. 1999, 71. 1474.

7. Oliver K. D.: Pleil J. D.: MeClenny. W. A. Amos. Emirom. 1986. 20, 1403 .

8. Gholson. A. R.: Jayanty. R. K. M.: Storm. J. F. Anal Chem. 1990. 62.1899

9. Kelly, T. J.: Holdren. M. W. Amos. Eminon. 1995. 29.2595.

10. Cao X. L: Hewitt. C. N. J. Chromatogr: A 1994. 688, 368.

11. Dewulf J. Langenhove. H. V. Amos. Emiron. 1997. 31.3291

12. Kim. Y. M.: Harad, S. Harrison, R. M. Einiron. Sci. Techmol 1999. 33.4342 .

13. Kuo. H. W. Wei. H. C.: Liu. C. S.: Lo. Y. Y.: Wang. W. C.: Lai. J. S.: Chan. C. C. Amos Emiron. 2000. 34.3331.

14. Willians. R. L.: Lipan, F.: Potter. R. A. J. Air Waste Manage. Assoc. 1990. 40.747

15. Pau, I. C.: Knoll I. E.: Midgett. M. R. $J$. Air Waste Manage. Assoc. 1991. HI. 1095

16. Wang. Y: Raihala. T. S.: Jackman. A. P.: John. R. St. Emiron. Sci. Technol. 1996. 30.3115.

17. Matisota. E.: Skrabakova, S.J. Chromatogr it 1995. 707, 145.

18. Wang. J. L.; Chen, S. W. Chew C. J. Chromatogr A 1999. 863. 183
19. Arthur, C. L.: Pawliszyn, J. Anal Chem. 1990. 62, 2145.

20. Zhang. Z.: Yang. M. T.: Pawliszyn. T. And Chem. 1994. 66. 844.

21. Gorlo. D.: Wolska. L.: Zygmunt. B.: Namiesnik. J. Talanta 1997. H. 1543.

22. Eriksson, M.: Swartling, A.; Dalhammar, G. Appl Microbiol. Biotechol. $1998,50.129$.

23. Zhang. Z.: Pawiszyn. J. J. High. Resolut. Chromatogr. 1993, 16. 689 .

24. Gorecki. T.: Pawliszyn. T. Anal Chent 1995.67. 3265.

25. Llompart. M.: Li. K.: Fingas. M. J. Chronatogr A 1998. 82+. 53.

26. Lord. H: Pawliszyn, J. J. Chomatogr: A $2000,885.153$.

27. Llompart. M.: Li, K.: Fingas. M. Anal Chem. 1998, 70.2510.

28. Pawliszin, J. Solid Phase Honextraction, Wiley-VCH: New York, 1997.

29. Potter. D. W.: Pawliszyn. T. Enwron. Sci. Technol. 1994. 28. 298.

30. Chai. M.: Arthur. C. L.: Pawliszyn. T. Anahyt 1993. 118. 1501.

31. Buchholz. K. D.: Pawliszyn. J. Anat Chem 1994, 66, 160.

32. Buchholz. K. D.; Pawliszyn, J. Enim. Sci. Techlol 1993. 27. 2844.

33. Bartak. P.: Cap. L. J. Chrontatogr. A 1997. 767. 171.

34. Young. R.: Lopez-Avila. V. J. High Resolut. Chronatogr: 1996. 19.247.

35. Dugay. J.: Miege. C. Hennion, M. C. J. Chomatog: A 1998, 795. 27.

36. Volmer. D. A.: Hui. J. P. M. Arch. Environ. Contam Toxicol. 1998. 35. 1 .

37. Moder. M.: Popp. P.: Eisert. R.: Pawlizynt. T. F J. Anal. Chent 1999.363 .680 .

38. Hwang, B.; Lee, M. J. Chromatog: A 2000. 898,245

39. Ho. W. H; Hsieh, S. J. Anal. Chim. Acta 2001, 128.111.

40. Boyd-Boland. A. A.; Pawliszyn, J. J. Chromatogr At 1995, 704. 163.

41. Barnabas. I. J.: Dean. J. R.: Fowlis. T. R.: Owetl. S. P. J. Chomatogr A 1995. 705.305.

42. Magdic. S:- Bovd-Boland, A. A.: Jinno. K; Pawliszan, J. d. Chomatogr: A 1996. 736.219.

43. Jinno. K.: Muramatsu. T: Saito. Y: Kiso, Y.: Magdic. S. Pawliszyt1. J. J. Chrontatogr . A 1996. 75t. 137.

44. Choudhury. T. K.: Gerhardt. K. O.: Mawhinney. T. P. Emiron. Sci. Technol. 1996. 30.3259.

45. Sng. M. T: Lee. F. K.: Lakso, H. A. J. Chromatog: A 1997.759. 225 .

46. Valor, I.: Molto. J. C. Apraiz, D.: Font. G. J. Chromatogr. A 1997. 767. 195. 
47. Eisert. R: Levsen, K: Wuensch. G. J. Chromatogr: A 1994. 683. 175.

48. Wu. J.: Mester. Z.: Pawliszyn. J. Anal Chim. Acta 2000. 424. 211.

49. Poerschmantn. J.: Kopinke. F. D.: Pawliszyn. J. Enwiron. Sci. Techlol. $1997,31.3629$.

50. Pan, L.: Adanns. M: Pawliszyn. J. And. Chem. 1995. 67.4396.

51. Gorecki. T.: Pawliszyn. J. Anal. Chem. 1996. 68. 3008.

52. Stashenko. E. E.: Puertas. M. A.: Salgar. W. Delgado. W.: Martinez. J. R. J. Chromatogr A 2000. 886. 175.

53. Mills. G. A.: Walker. V: Mughal. H. J. Chromatogt: B 1999. 723. 281.

54. Kataoka, H.: Lord. H. L.; Pawliszyn. I. J. Chromatogr: B 1999. 731,353 .

55. Elke. K.: Jermann. E.: Begerow. J.: Dunemann. L. J. Chronatogr. A 1998. 826. 191.
56. Yassaa. N.: Meklati, B. Y:; Cecinato, A. J. Chromatogr. A 1999. $8+6.287$.

57. Dermietzel. T.: Strenge. G. F J. Anal Chem. 1999. 36t. 645.

58. Gorlo. D.: Zygmunt. B.: Dudek. M.: Jaszek. A.: Pilarezyk. M.: Namiesnik. J. F . Anal Chem 1999.363,696.

59. Haberhauer-Trover. C.: Rosenberg. E.: Grasserbauer, M. d. Chromatogr: A 1999. 848. 305 .

60. Bartelt. R. T.: Zilkowski. B. W. Anal Chem 1999. 71.92.

61. Page. B. D.: Lacroix. G. J. Chomatogr: A 2000. 873. 79.

62. Elmore. J. S.: Mottram. D. S.: Hierro. E. J. Chromatogr . 2000. 905.233.

63. U.S. EPA, Method 18. Code of Federal Regulations, 1987, Part 60: Title 40; Appendix A. Alpendurada. M. J. Chromatog: A 2000. 889.3 .

64. Chai. M.: Pawliszyn. J. Emiron. Sci. Technol 1995. 29. 693. 